\title{
FGFR2 Protein Variant
}

National Cancer Institute

\section{Source}

National Cancer Institute. FGFR2 Protein Variant. NCI Thesaurus. Code C107581.

A variation in the amino acid sequence for the fibroblast growth factor receptor 2

protein. 